\title{
Pharmacognostical and Antimalarial Studies of Tamarindus indica Leaves
}

\section{Dr. Md. Rageeb Md. Usman*, Badgujar Pallavi Sunil ${ }^{1}$}

${ }^{* 1}$ Department of Pharmacognosy, Smt. Sharadchandrika Suresh Patil College of Pharmacy, Chopda, Maharashtra, India

\begin{abstract}
The present study was performing to know Antimalarial activity of Tamarind (Tamarindus indica L.) The plant T. indicus was collected further by using methanol the extract residue diluted 10\% Dimethyl sulphoxide extract from which were produced. The plate diffusion method was used as an antimicrobial testfor Plasmodium falciparum and Plasmodium vivax by zone of inhibition tested.TLC standardization ensure presence of tartaric acid in the extracted sample against the standard.leaves possess an near to standard Antimalarial activity which was confirmed by its effect on experimental living organism.
\end{abstract}

Keyword: Tamarindus Indica, Leaf, Antimalarial Activity, TLC.

\section{INTRODUCTION}

Tamarind (Tamarindusindica L.) belongs to the family of Fabaceae (Leguminosae), subfamily Caesalpinioideae, is a very important food within the tropics. Medicinal plants are the rear bone of traditional medicine (TM). TM is vital in tropical countries: Contrary to pharmaceuticals, pharmacological, and pharmacotherapy. T. indicais employed as TM in India, Africa, Pakistan, Bangladesh, Nigeria, and most of the tropical countries. It is used traditionally in abdominal pain, diarrhea and dysentery, helminths infections, wound healing, malaria and fever, constipation, inflammation, cell cytotoxicity, gonorrhea, and eye diseases. It is numerous chemical values and is rich in phytochemicals, and hence, the plant is reported to possess antidiabetic activity, antimicrobial activity, antivenomic activity, antioxidant activity, antimalarial activity, hepatoprotective activity, antiasthmatic activity, laxative activity, and antihyperlipidemic activity. The plant contains in leaves, seeds, roots, pulp, fruits, and flowers an excellent sort of bioactive substances that have beneficial effects on human health and therefore the possibility of application in various tropical, pharmaceutical, and industrial sectors [1-3].

Medicinal plants are the rear bone of traditional medicine (TM). TM is vital in tropical countries: Contrary to pharmaceuticals, pharmacological, and pharmacotherapy. It is often freely and readily available multipurpose tree of which just about every part finds a minimum of some use either 
medicinal or nutritional. For instance, in Burkina Faso, up to $90 \%$ of the population relies to use traditional remedies. Tamarind is indigenous to tropical Africa, but it is been introduced and naturalized worldwide in over 50 countries. Plants are the essential elements of TM and selected as a therapy in greater amounts [4,5].

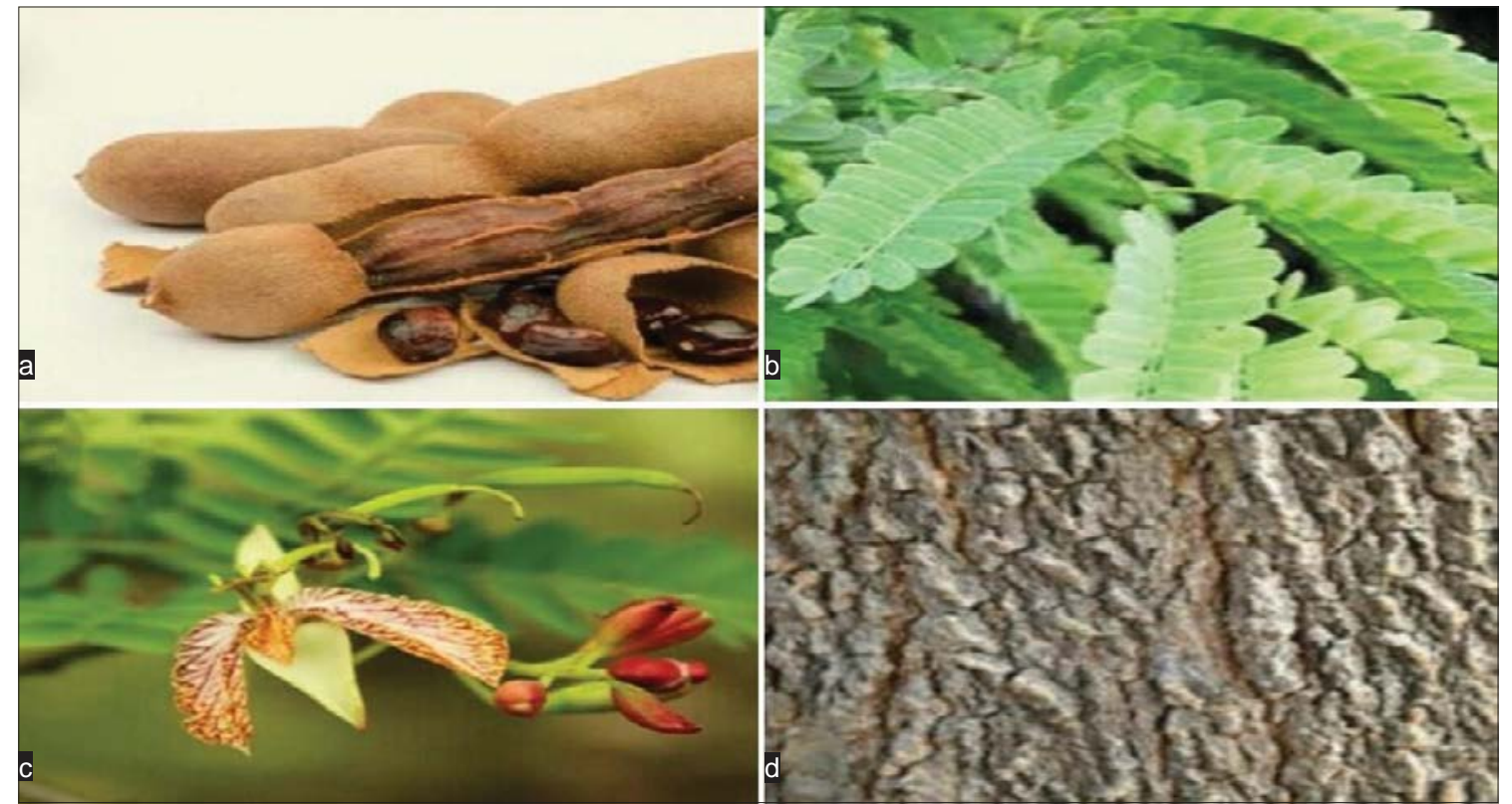

Figure 1: (a) Fruits, (b) leaves, (c) flowers, (d) stem bark of Tamarindus indica MATERIAL AND METHODOLOGY

\section{Plant Collection and Authentication}

There are several species available from same genus as well as there could be resemblance in physical appearance with other plants so the authentication of the plants under study is essential part of the protocol. Authentication ensures the correct plant species and plant parts used as raw materials for scientific study of medicinal plants. The plant T. indicus was collected from Department of Pharmacognosy, College of Pharmacy, Chopda (Jalgaon, Maharashtra) and was identified and authenticated by Botanical Survey of India, Pune.

\section{Extraction of Active Constituents from T. Indicus leaves}

Approximately fifty (50) gram each of powered leaves and fruits were each macerated in $500 \mathrm{ml}$ of distilled water and methanol respectively for period of 24 hour at room temperature.

Each preparation was filtered through a Whatman filter paper and the aqueous filtrate was evaporated to dryness in water bath at $400 \mathrm{C}$ while methanol extract in rotary evaporator at 500C.

The residue obtained was further diluted using 10\% Dimethylsulphoxide (DMSO) to produce 100 $\mathrm{mg} / \mathrm{ml}$ of the extract from which various concentrations of 50,40,30, 20 and 10mg/ml were produced [6,7]. 


\section{Standardization of Plant Extract}

Crude tartaric acid extract (10 $\mu \mathrm{l}$ each) solution was used for the chromatographic method to identify and isolate the pure tartaric acid. The mobile phase selected for use was n-Propanol: $n$ - Butanol: Ammonia in a ratio of 7:1:2 Spots were detected by using $1 \%$ solution of vanillin in methanolic sulfuric acid as chromatogenic reagents and viewed under ultraviolet light at $365 \mathrm{~nm}$ wavelength for identification of the separated compounds. The $\mathrm{Rf}$ value of sample was determined to ensure presence of tartaric acid in the extracted sample against the standard [8-10].

\section{In Vitro Pharmacological Evaluation of Tamarindus indicus Leaves Evaluation of antimicrobial activity}

The plate diffusion method in sterile $20 \mathrm{ml}$ petri dishes was used as an antimicrobial test. Inoculated plates were incubated at $37^{\circ} \mathrm{C}$ for $24 \mathrm{~h}$ for Plasmodium falciparum and Plasmodium vivax. The antibacterial activity of the tested substances was shown by a clear zone of inhibition around the application point. Seven tamarind leaf methanolic extracts were evaluated against Hydrochloroquine used as reference. The dose of fluid extracts was $10 \mu \mathrm{l} /$ plate. Positive controls were Hydrohloroquine (30 $\mu \mathrm{g}$ ), while solvents were employed as negative control.

\section{Determination of the minimum inhibitory concentration}

The broth dilution method approved by the National Committee for Clinical Laboratory Standard (NCCLS) was followed for those extracts that exhibited some activity in the plate diffusion method. Briefly, for all extracts, a series of two fold dilutions was prepared in $1 \mathrm{ml}$ of MuellerHinton broth. Aqueous extracts ranged from 0.15 to $0.001 \mathrm{~g} / \mathrm{ml}$ (leaves weight/volume), while for hydroalcoholic fluid extracts, the doses evaluated varied from 1.5 to $0.01 \mathrm{~g} / \mathrm{ml}$ (leaves weight/volume). For the essential oils, doses ranged from the equivalent of 40 to $0.31 \mu$. Test microorganisms were previously diluted to 0.5 McFarland turbidity standard for bacterial isolates. Other tubes containing only nutrient broth and the standard antibiotic Hydrochloroquine were also seeded with the test organisms to serve as controls. All the tubes were incubated at $35^{\circ} \mathrm{C}$ for $24 \mathrm{~h}$, while tubes containing yeast cultures were incubated for $48 \mathrm{~h}$. After incubation, the tubes were examined for microbial growth by observing turbidity. Those visual observations were confirmed by measuring the optical density of the solution at $620 \mathrm{~nm}$ in the spectrophotometer aforementioned, establishing the minimum inhibitory concentration (MIC). To determine the minimum bactericide concentration (MBC), aliquots of $100 \mu 1$ from all dilutions not showing any growth were inoculated on sterile Mueller-Hinton agar plates. Inoculated 
plates were incubated at $35^{\circ} \mathrm{C}$ for $24 \mathrm{~h}$ for all bacteria, while those inoculated with fungi were incubated for $48 \mathrm{~h}$. MBCs were determined as the lowest concentration in which the extract evaluated did not allow growth of organisms on the agar plate. The presence of one or two colonies was disregarded [11].

\section{RESULTS AND DISCUSSION}

Crude tartaric acid extract (10 $\mu$ each) solution was used for the chromatographic method to identify and isolate the pure tartaric acid. The mobile phase selected for use was n-Propanol: $\mathrm{n}$ - Butanol: Ammonia in a ratio of 7:1:2 Spots were detected by using $1 \%$ solution of vanillin in methanolic sulfuric acid as chromatogenic reagents and viewed under ultraviolet light at $365 \mathrm{~nm}$ wavelength for identification of the separated compounds. The Rf value of sample was determined to ensure presence of tartaric acid in the extracted sample against the standard. The $\mathrm{Rf}$ value of 0.44 was found to be in accordance with the standard suring proper extraction of T. indicus leaves. TLC is given in Fig. 2.

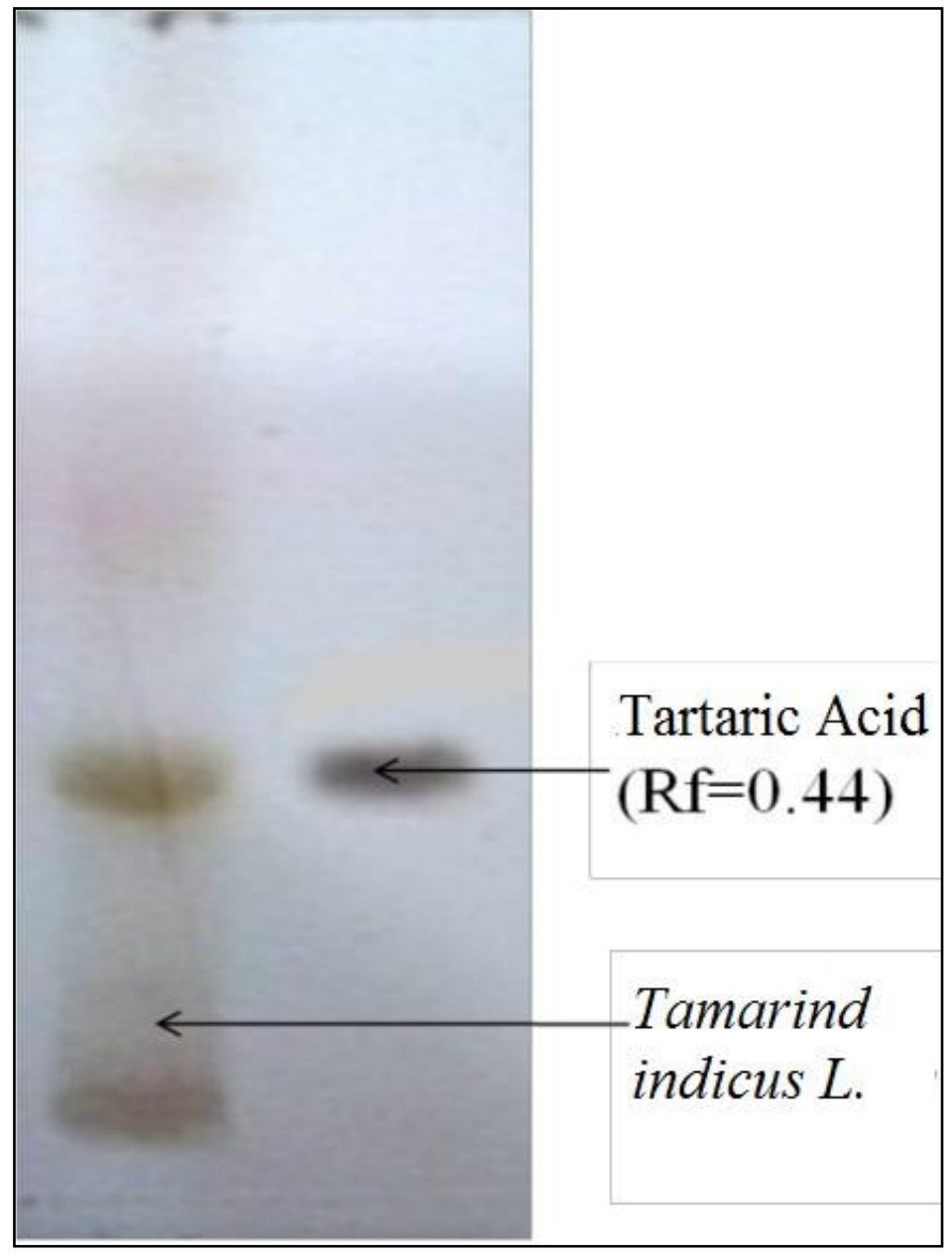

Figure 2: TLC standardization of T. Indicus Leaves 


\section{In Vitro Pharmacological Evaluation}

The plate diffusion method in sterile $20 \mathrm{ml}$ petri dishes was used as an antimicrobial test. Inoculated plates were incubated at $37^{\circ} \mathrm{C}$ for $24 \mathrm{~h}$ for Plasmodium falciparum and Plasmodium vivax. The antibacterial activity of the tested substances was shown by a clear zone of inhibition around the application point. Seven tamarind leaf methanolic extracts were evaluated against Hydrochloroquine used as reference. The dose of fluid extracts was $10 \mu 1 /$ plate. Positive controls were Hydrohloroquine (30 $\mu \mathrm{g})$, while solvents were employed as negative control. Results are illustrated in Table.

Table 1: Results obtained in the microbiological assay by plate diffusion method

\begin{tabular}{|c|c|c|c|}
\hline \multicolumn{2}{|c|}{ Investigational Agent } & Concentration & \multicolumn{2}{|c|}{ Inference } \\
\cline { 3 - 4 } & & $\begin{array}{c}\text { P. } \\
\text { falciparum }\end{array}$ & P. vivax \\
\hline $\begin{array}{c}\text { Methanolic Extract of } \\
\text { indicus }\end{array}$ & $5 \%$ & + & - \\
\cline { 2 - 4 } & $10 \%$ & + & + \\
\hline HCQ & $5 \%$ & + & + \\
\cline { 2 - 4 } & $10 \%$ & + & + \\
\hline
\end{tabular}

Table 2: MIC and MBC for tamarind extracts (leaves weight/volume)

\begin{tabular}{|c|c|c|c|c|}
\hline \multirow{2}{*}{ Microorganism } & \multicolumn{2}{|c|}{ T. Indicus Extracts } & \multicolumn{2}{c|}{ HCQ } \\
\cline { 2 - 5 } & MBC & MIC & MBC & MIC \\
\hline P. falciparum & 18.6 & 1.9 & 21.2 & 2.4 \\
\hline P. vivax & 21.3 & 4.8 & 24.8 & 3.7 \\
\hline
\end{tabular}

By the results obtained, it is clear that the methanolic extract of $T$. indicus leaves possess an near to standard Antimalarial activity which was confirmed by its effect on Plasmodium parastites cultures. Hence it can be concluded that the Objective was fulfilled through this experiments. 


\section{CONCLUSION}

Inoculated plates were incubated at $37^{\circ} \mathrm{C}$ for $24 \mathrm{~h}$ for Plasmodium falciparum and Plasmodium vivax. The antibacterial activity of the tested substances was shown by a clear zone of inhibition around the application point. Seven tamarind leaf methanolic extracts were evaluated against Hydrochloroquine used as reference. The dose of fluid extracts was $10 \mu \mathrm{l} /$ plate. Positive controls were Hydrohloroquine (30 $\mu \mathrm{g}$ ), while solvents were employed as negative control. By the results obtained, it is clear that the methanolic extract of $\mathrm{T}$. indicus leaves possess an near to standard Antimalarial activity which was confirmed by its effect on experimental living organism. Hence it can be concluded that the Objective was fulfilled through thisexperiments.

\section{CONFLICT OF INTEREST}

Authors have no conflicts of interest to declare.

\section{ACKNOWLEDGEMENTS}

The authors are thankful to the Management and Principal, Smt. Sharadchandrika Suresh Patil College of Pharmacy, Chopda, Maharashtra, India for providing necessary facilities for research work.

\section{REFERENCES}

1. Bhadoriya SS, GaneshpurkarA, Narwaria J, Rai G, Jain AP. Tamarindusindica: Extent of explored potential. Pharmacognosy reviews. 2011Jan;5(9):73.

2. De Caluwé E, HalamouáK, Van Damme P. AdansoniadigitataL.-A review of traditional uses, phytochemistry and pharmacology. Afrika focus. 2010 Feb25;23(1):11-51.

3. Van Wyk BE. A review of commercially important African medicinal plants. J Ethnopharmacol2015;176:118-34.

4. De Caluwé E, HalamouáK, Van Damme P. TamarindusindicaL.-A review of traditional uses, phytochemistry and pharmacology. Afrika focus. 2010 Feb25;23(1):53-83.

5. Ishola MM, Agbaji EB, Agbaji AS. A chemical study of Tamarindusindica (Tsamiya) fruits grown in Nigeria. Journal of the Science of Food and Agriculture.1990;51(1):141-3.

6. Dhasade VV, Nirmal SA, Patil RY. Pharmacognostic and Phytochemical Evaluation of TamarindusindicaLinn. Leaves. Journal of Current Pharma Research.2018;8(2):2310-20. 
7. Satpute SB, Vanmare DJ. In vitro antifungal activity of Tamarindusindica L. extract against pathogenic fungi. International Journal of Botany Studies. 2017May;2(3):25-8.

8. Sandesh P, Velu V, Singh RP. Antioxidant activities of tamarind (TamarindusIndica) seed coat extractsusing in vitro and in vivo models. Journal of food science and technology. 2014 Sep;51(9):1965-73.

9. Jadhav DY, SahooAK, Ghosh JS, Ranveer RC, Mali AM. Phytochemical detection and in vitro evaluation of tamarind fruit pulp for potential antimicrobial activity. International Journal of Tropical Medicine.2010;5(3):68-72.

10.AP LL, Chrysostomo TN, Azzolini AE, Recchia CG, Uyemura SA, de Assis-Pandochi AI. Effect of the extract of the tamarind (Tamarindusindica) fruit on the complementsystem: studies in vitro and in hamsters submitted to a cholesterol-enriched diet. Food and chemical toxicology: An international journal published for the British Industrial Biological Research Association. 2007 Feb 17;45(8):1487-95.

11.Escalona-Arranz JC, Péres-Roses R, Urdaneta-Laffita I, Camacho-Pozo MI, RodríguezAmado J, Licea-Jiménez I. Antimicrobial activity of extracts from TamarindusindicaL. leaves. Pharmacognosy Magazine. 2010 Jul;6(23):242. 